\title{
Association of Psychological Factors with Chance of Developing Preeclampsia: A Systematic Review and Meta-Analysis
}

\author{
Dina Abadi-Bavil ${ }^{1}$, Nasibeh Sharifi ${ }^{2}$, Tayebeh Rashidian ${ }^{3}$, Reza Pakzad $^{4}$ \\ 1.Instructor, Department of Midwifery, School of Medicine, Mashhad Branch, Islamic Azad University, Mashhad, Iran. \\ ORCID ID: 0000-0003-3895-438X. \\ 2.Assistant Professor, Department of Midwifery, School of Nursing \& Midwifery, Ilam University of Medical Sciences, \\ Ilam, Iran., (Corresponding Author), Email: nasibe.sharifi@ yahoo.com. Tel: 084-32227134, ORCID ID: 0000-0002-0734- \\ 2463. \\ 3.Assistant Professor, Department of Gynecology, School of Medicine, Ilam University of Medical Sciences, Ilam, Iran. \\ ORCID ID: 0000-0003-4119-8757. \\ 4.Assistant Professor, Department of Epidemiology, School of Health, Ilam University of Medical Sciences, Ilam, Iran. \\ ORCID ID: 0000-0001-8133-3664.
}

Background and Aim: Preeclampsia is the third leading cause of maternal mortality in the world and the second most common cause of death in pregnant mothers in Iran. Psychosocial aspects have been recently considered as a risk factor for developing preeclampsia. The purpose of this study was to determine the association between psychological factors and the chance of developing preeclampsia.

Materials and Methods: This systematic review and meta-analysis was performed based on the studies conducted in the world. We searched seven databases (Irandoc, SID, Magiran, Iranmedex, PubMed, Scopus, Web of science, Cochrane, ISI, and Embace databases), by using keywords of psychological factors, stress, anxiety, depression, and preeclampsia to find relevant articles published between 2008- 2018. Data from relevant studies were extracted by two persons separately and evaluated by using the Stroop checklist. After extracting the required data, they were combined using a random model and the heterogeneity of the studies was evaluated by the I 2 indices. STATA-11 software was used for data analysis.

Results: In the present study 11 articles were analyzed. The total number of samples in the study was 658678. The chances of preeclampsia in individuals with stress, anxiety, depression, and those exposed to violence were estimated to be $1.21,3.07,3.04$, and 2.37 , respectively.

Conclusion: Considering the importance of preeclampsia in pregnancy and its impact on maternal and fetal health, basic measures should be taken to prevent it by identifying people at risk and the contributing factors, such as routine screening of psychological factors before and through the pregnancy semesters.

Keywords: Psychological Factors, Stress, Anxiety, Depression, Preeclampsia

Received: Apr 23, 2019 Accepted: Oct 3, 2020

How to cite the article: Dina Abadi-Bavil, Nasibeh Sharifi, Tayebeh Rashidian, Reza Pakzad . Association of Psychological Factors with Chance of Developing Preeclampsia: A Systematic Review and Meta-Analysis. SJKU. 2021;26(1):126-138.

Copyright (C) 2018 the Author (s). Published by Kurdistan University of Medical Sciences. This is an open access article distributed under the terms of the Creative Commons Attribution-Non Commercial License 4.0 (CCBYNC), where it is permissible to download, share, remix, transform, and buildup the work provided it is properly cited. The work cannot be used commercially without permission from the journal 


\section{ارتباط بين عوامل روانى با شانس ابتلا به يره اكلاميسى: مرور سيستماتيك و متآناليز}

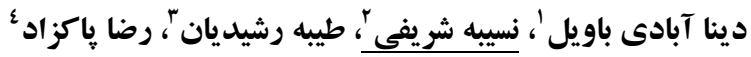

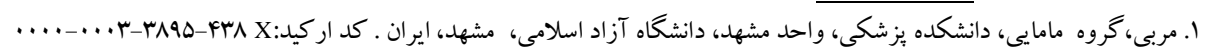

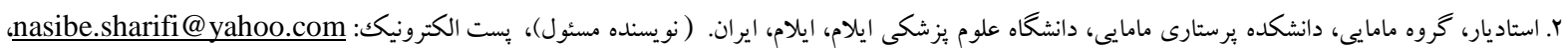
تلفن:

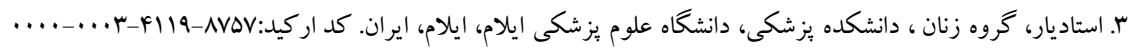

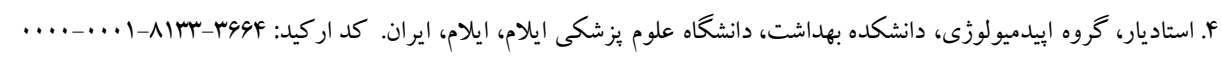

جكکيه

زمينه و هدف: بره اكلاميسى سومين علت مرگك مادران باردار در جهان و دومين علت شايع مرگك مادران باردار در ايـران اسـت. اخيـراً جنبـه هـاى روانسى اجتماعى به عنوان عامل خطرى در بروز اين اختلال مورد توجه قرار گرفته است. هدف از مطالعه حاضـر، تعيين ارتباط بين عوامل روانى با شانس ابتلا به يره اكلاميسى مى باشد. مواد و روش ها: اين مرور سيستماتيكك و فراتحليل بر اسـاس مطالعـات انجـام شـده در جهان انجـام شـده اسـت. هفـت بايخـاه اطلاعـاتى ISI ،Cochrane ،Web of Science ، Scopus ،PubMed Iranmedex ،Magiran ،SID ،Irandoc Embace با استفاده از كليد وازه هاى عوامل روانى، استرس، اضطراب، افسردگى، يره اكلاميسى و معـادل انكليسى آنها بـراى

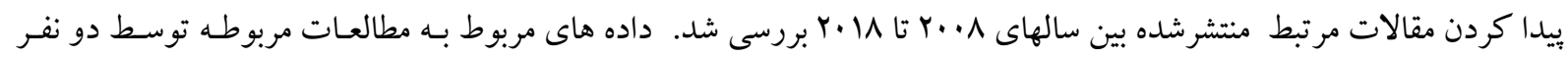
جداگًانه استخراج و با استفاده از جكك ليست استروبٍ ارزيابى شد. يّ از استخراج داده هاى مورد نياز، با استفاده از مدل تصادفى با هم تر كيب شده و ناهمخنى مطالعات با استفاده از شاخص I2 بررسى شد. نرم افزار STATA نسـه Iل 12 بـراى آناليز داده هـا استفاده شد.

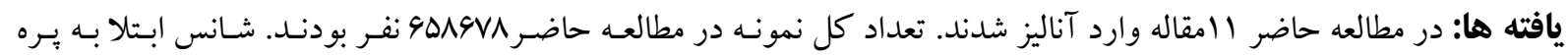

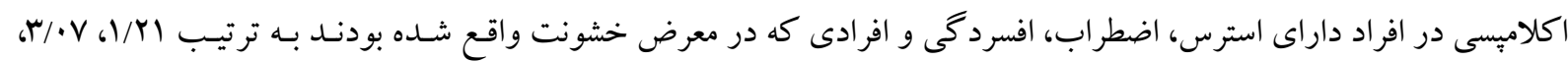
.

نتيجه كيرى: با توجه به اهميت اين بيامد مهم در بـاردارى و تـاثير بـر سـلامت مـادر و جنسين بايسـ اقـامات اساسى در جهـت يبشگيرى از وقوع آن از طريق شناسايى افراد در معرض خطر و عوامل موثر در بروز آن مانند غربالخرى روتين عوامل روانى قبل از باردارى و در هر سه ماهه باردارى صورت گيرد. وازه هاى كليدى: عوامل روانى ، استرس، اضطراب، افسردگى، يره اكلاميسى

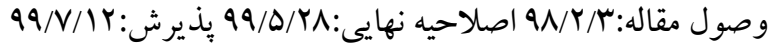


شايعتر از مردان است كه اين ميزان در زنـان واقع در سـنين

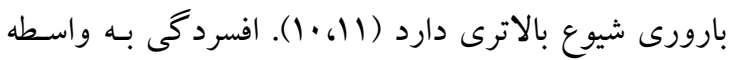

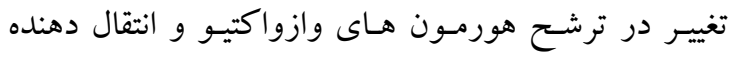
هاى عصبى- هورمونى كه عامل القاى تغييرات عروقى دوران باردارى هستند، منجر به انقباض عروقى و مقاومـت فئس عروق رحمى و در نتيجه افزايش فشارخون مى شود. همجِين با تأثير بـر فعاليت پِلاكتها، كاهش تغيير ضربان قلب

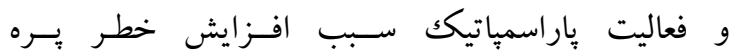
اكلاميسـى نيـز مسى شــود (Y) (1). نتايج برخى از مطالعات بيانكر ارتباط مثبتى بين جنبه هاى روانى مادر و و يره

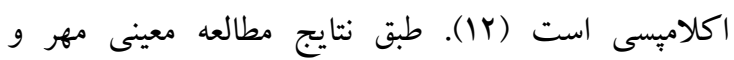

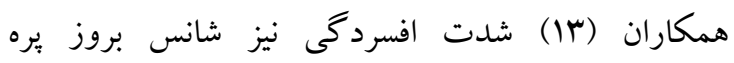

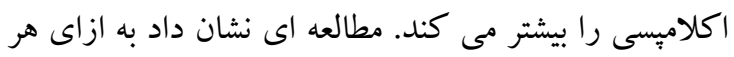

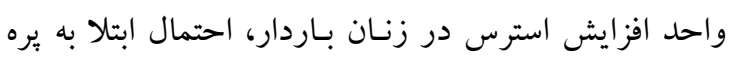

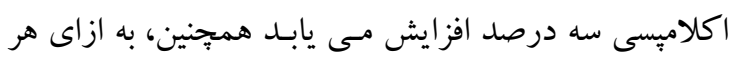
واحد افزايش حمايـت اجتمـاعى در زنـان بـاردار، احتمـال

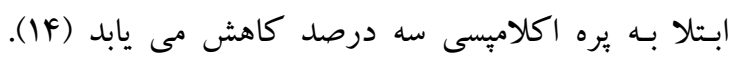

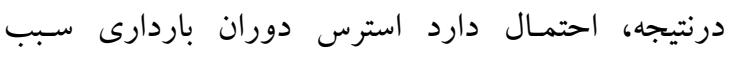

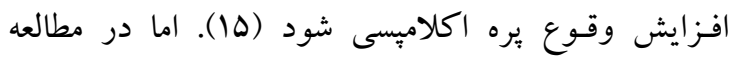

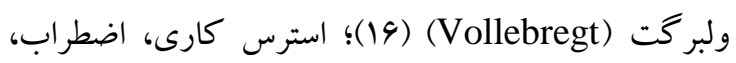

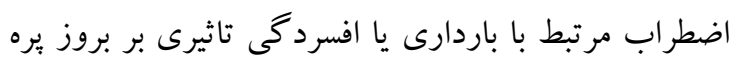

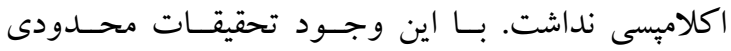

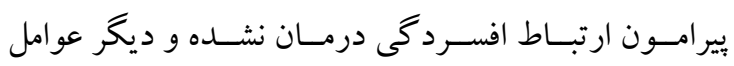

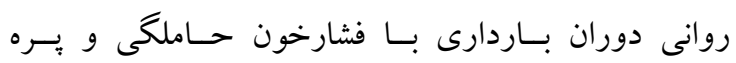

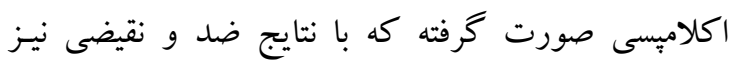
همراه بـوده است. با توجه به عوارض يره اكلاميسى براى مادر و نوزاد و ناشناخته بودن اتيولوزى و در نتيجه اهميت غربالكرى زنان باردار از نظر عوامل خطر ايـن بيمـارى و از وناز

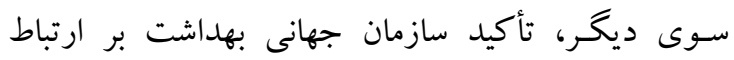
عوامل روانى اجتماعى با بيمارى ها و در نهايت كـم بودن اطلاعات در اين زمينه، يُزوهش حاضر با هـدف تعيين ارتباط عوامل روانى با شانس ابتلا به يُه اكلاميسى انجـام

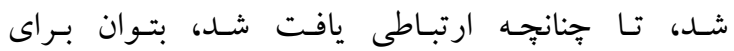

مقدمه

بره اكلاميسى شايع ترين نوع اختلال فشار خون در باردارى

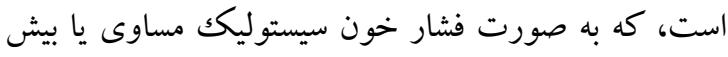

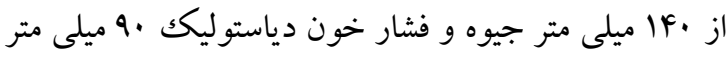
جيوه يا بيشتر همراه با دفع ادرارى بروتئين بعد از هفته بيستم

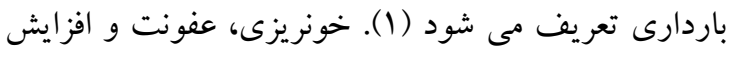

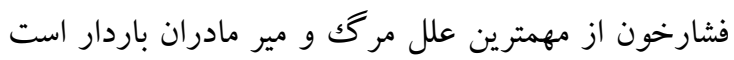
(Y). شيوع يره اكلاميسى در كشورهاى مختلف متفاوت

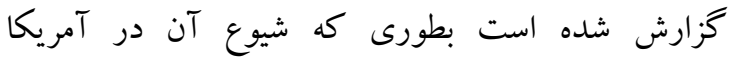

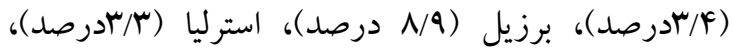
بنگكلادش (ץ/ادرصد)، هندوستان (r/r/درصد) و و تايلند

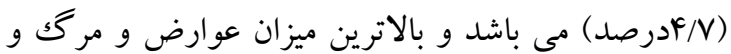

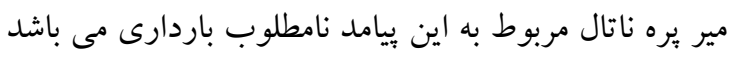

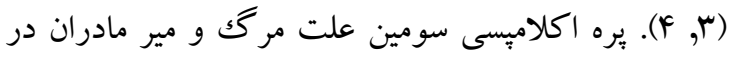
جهان و دومين علت شايع مرك مادران در ايران است (ه). درصورت بيشرفت، اين يِيامد باردارى منجر به عوارض

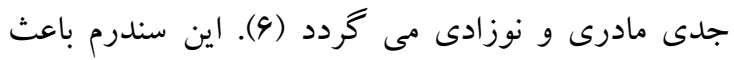

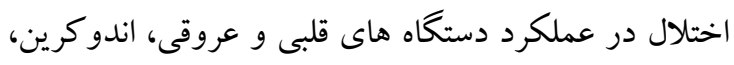

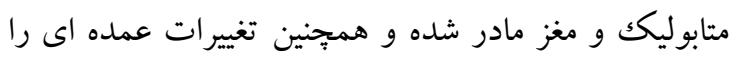
در جريان خون محيطى ايجاد مى كند كه مهمترين عامل

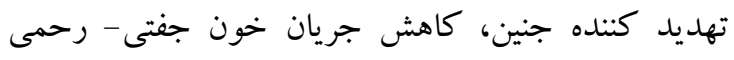

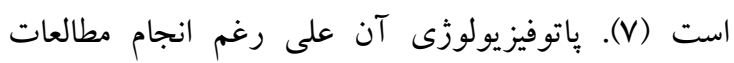

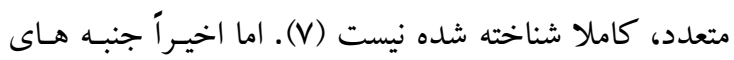

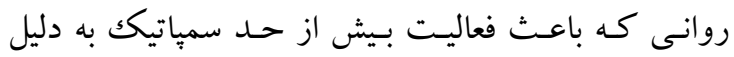
تحريكك سيستم عصبى اتونوم مى شوند، به عنوان عامل خطرى در بروز اين اختلال مورد توجه قرار گرفته است

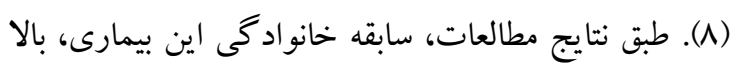
بودن شاخص توده بدنى، سن بالاى مادر هنگام باردارى و

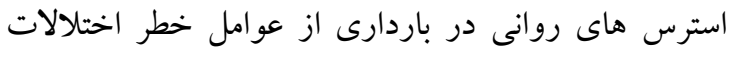

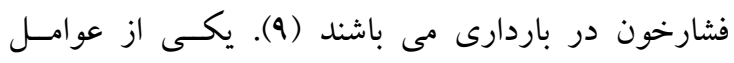

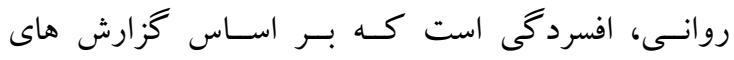
سازمان جهانى بهداشت تا سال . r.r.r. دومين بيمارى شايع

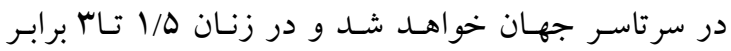


متن كامل مقالات در اختيار مرورگ ها قرار گرفت. هر مقاله توسط دو نفر مرورگر و به طور مستقل مطالعه شد و جهت ارزيابى مطالعات از ابزار استروب استفاده شد و در هر هر هر مرحله در صورت وجود ابهام با انجام بحث، به توافق مى رسيدند. در صورت رد شدن مقاله، دليل رد آن ذكر شد. در مرحله بعد مقالات يافت شده بر اساس معيارهاى ورود و

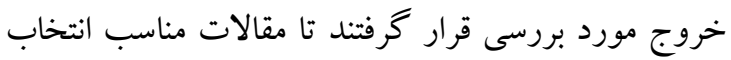
معيار هاى ورود و خروج مطالعه: شامل 1. مطالعاتى كه در جهان انجام شده اند، ז. مطالعات مشاهده اى (مقطعى، مورد شاهد و همخروهى)، r. مطالعاتى

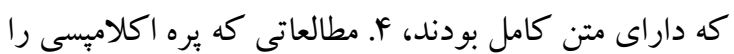

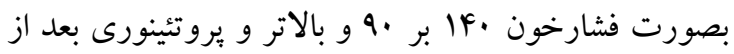

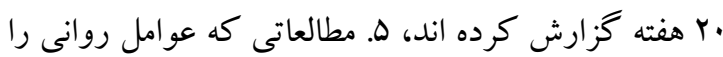
از طريق برسشنامه سنجيده اند. معيارهاى خروج مقالات هردات

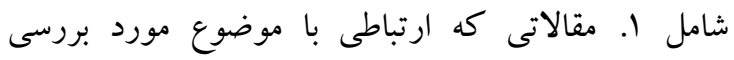

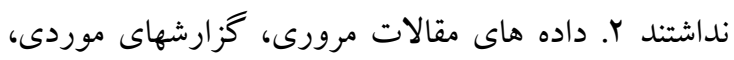

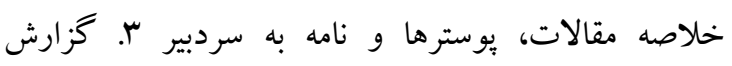

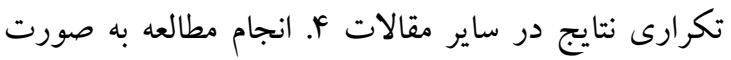

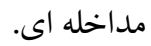

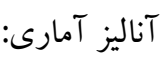

اندازه اثر مورد استفاده در اين متآناليز نسبت شانس (OR) مى باشد؛ كه برابر است با شانس مواجهه در افراد داراى ييامد به شانس مواجهه در افراد سالم (بدون يِامد). بدين دليل از نسبت شانس استفاده شد؛ كه براى مطالعات كوهورت، مقطعى و مورد شاهد قابل محاسبه است (IV). انجام متآناليز با به دست آوردن نسبت شانس و حدود اطمينان هף درصد، براى هر مطالعه انجام شد. در صورتى كه مطالعه از شاخصى غير از نسبت شانس استفاده كرده بود، با استخراج ديتا از مطالعه محقق نسبت شانس محاسبه

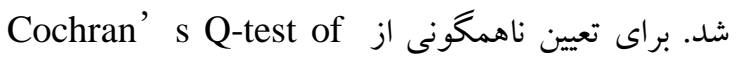
heterogeneity ناهمخًنى از شاخص I2 استفاده شد. براساس طبقه بندى

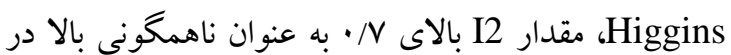

ييشگیىى و كاهش اين بيمارى، راهكارهاى را براى زنان

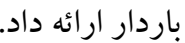

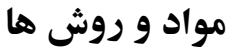
مطالعه مرور سيستماتيك و متاآناليز حاضر جهت تعيين ارتباط بين عوامل روانى با بروز بره اكلاميسى در جهان انجام شد. نتايج اين مطالعه بر اساس مطالعات انجام يافته در

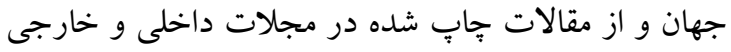

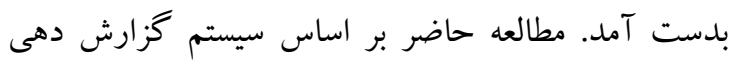
مطالعات سيستماتيك و متآناليز طبق مراحل زير انجام

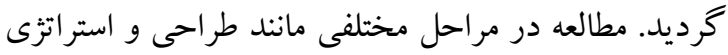
جستجو، جمع آورى مقالات و بررسى سيتماتيك آنها، بررسى معيارهاى ورود و خروج، ارزيابى كيفى و نهايت آناليز آمارى داده ها انجام شد.

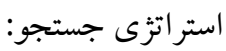
در اين مطالعه مرور نظام مند، بانكك هاى اطلاعاتى داخلى جلى مانند SID ،Iranmedex Magiran،Irandoc و و ساير بايخاه ها براى جستجوى مقالات لاتين مانند PubMed، ،ISI ،Cochrane ،Web of science ،Scopus Embace

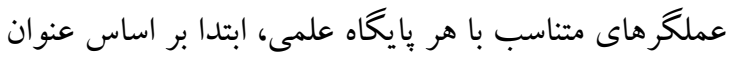

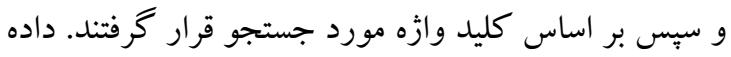

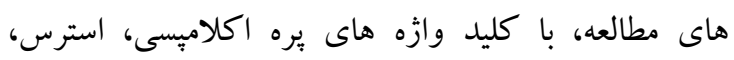
اضطراب، افسردگى، خشونت، عوامل روانى و تركيبات احتمالى آنها براى مقالات فارسى و معادل انكليسى آنها

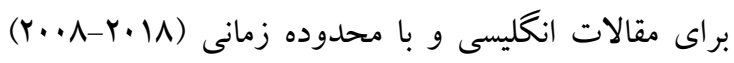
جمع آورى گرديد. انتخاب مطالعات و استخر اج داده ها: يزووهشخر ابتدا تمام مطالعات و مقالات مرتبط بات باد ارتباط

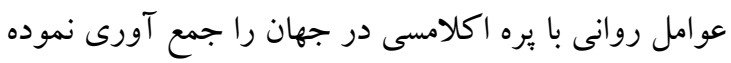
و پِ از اتمام جستجو، مقالات تكرارى حذف شدند. در

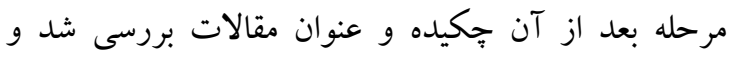

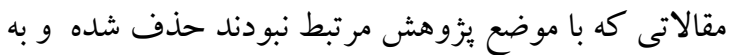

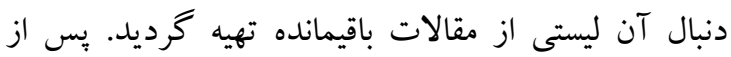
مخفى كردن مشخصات مقالات شامل نام مجله و نام مؤلف، همله علمى دانشكاه علوه بِزشكى كردستان / دوره بيست و شش / فروردين و ارديبهشت م.ع|| 
مسار ارتباط بين عواهل (وانى...

تخمين زده شد و سبِ مطالعات حذف شده دوباره به نمودار اضافه شد تا مقدار واقعى اندازه اثر تخمين زده شود. سطح معنى دار در تمام اناليز ها هـ/ در نظر كرفته شد. Stata version ) If تمام اناليز ها با نرم افزار استيتا ورزئ (14.0(College Station Texa) مراحل انتخاب مقالات در شكل ا نشان داده شده است. با استفاده از كليد وازه هاى ذكر شده به صورت تركيبى يا به تنهايى، جستجو صورت گرفت و YMN مقاله مربوط به اضطراب، له مقاله درخصوص در معرض خشونت

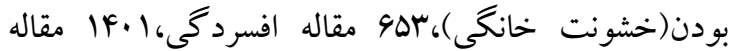
استرس و لهالمقاله روانى شناسايى شد. طى مرور سيستماتيك و ارزيابى نهايى، 11 مطالعه مورد بررسى و تجزيه تحليل آمارى قرار گرفت.
نظر كرفته شد. به منظور برآورد ادغام شده نسبت fix- (Pooled estimate of odds ratio ( شانس effect model استفاده شده و هر جاى كه مقدار ناهمكونى بالاى V/ • بود از Random-effect model استفاده شد. از meta-regression method روانى، نوع مطالعه، حجم نمونه و تاريخ جاب به عنوان عوامل موثر بر ناهمخًونى بين مطالعات استفاده شد. از دستور metabias براى بررسى وجود سوگرايى انتشار(Publication Bias) و از funnel plot براى نمايش سوگرايى انتشار استفاده شد و در صورت وجود سو گرايى انتشار با دستور metatrim با استفاده از روش مقدار تورش انتشار adjust trim and fill روش در ابتدا مطالعات كوجّك كه باعث عدم تقارن در نمودار شده بودند، حذف شدند و سيس مركز نمودار

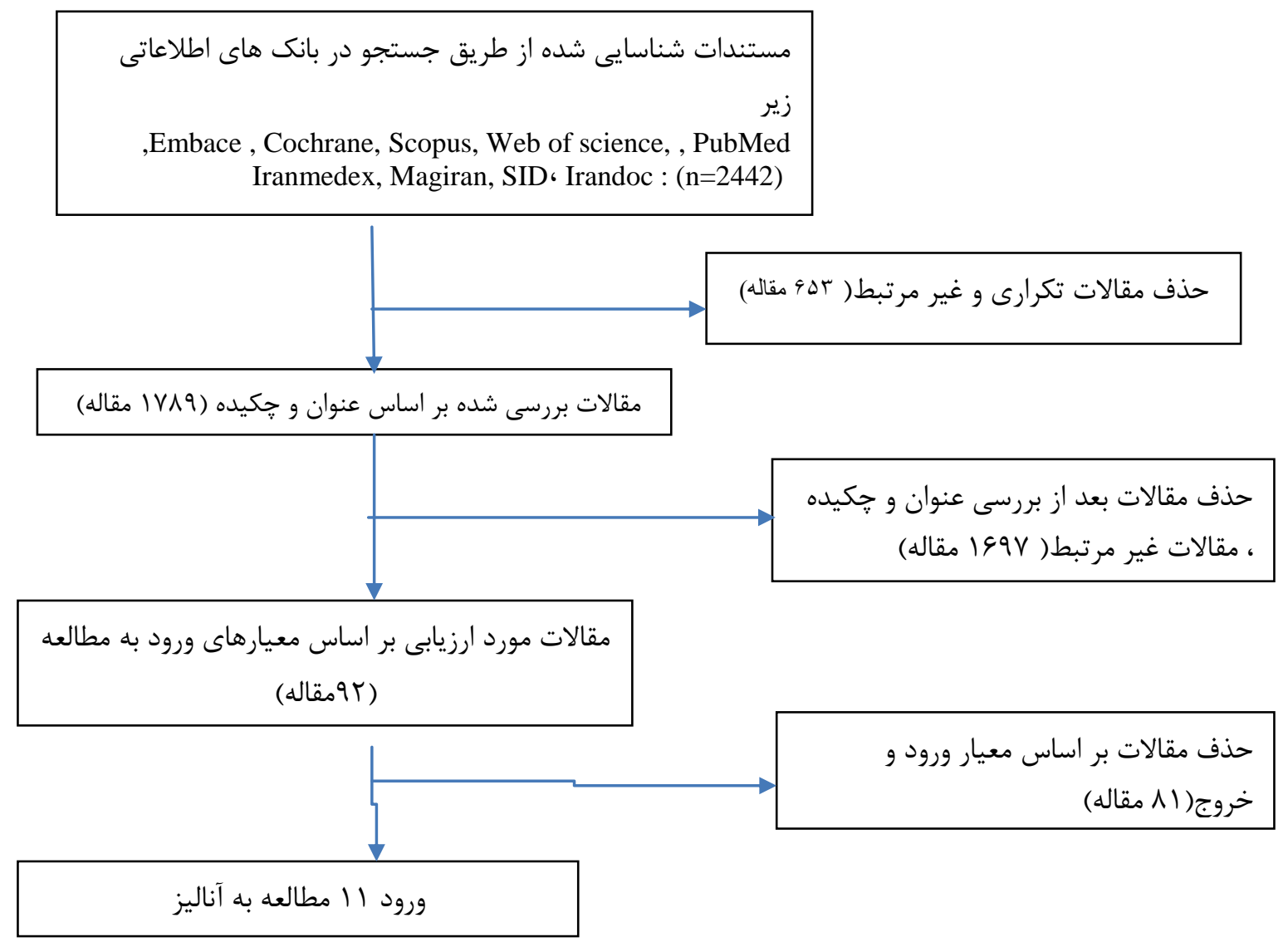

شكل 1. فلوجارت مراحل انتخاب مطالعات در ثئوهش 
نتايج هتروزنيستى و يابليكشن باياس:

Cochran's Q-test of heterogeneity براساس هتروزنسيتى معنى دارى بين مطالعات وجود دارد(P) برابر M درصد بود كه حاكى از مقدار بالاى ناهمكنى است. جدول شماره Y، نتايج متار كر سيون يك طرفه ( Univariate Meta-regression را نشان مى دهد. بر اين اساس نوع طراحى مطالعه رابطه مستقيم معنى دارى با نسبت شانس

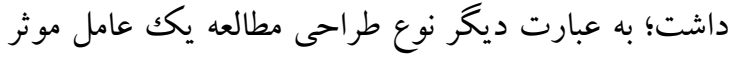
بر هتروزنيستى بود. هر جند رابطه معكوس بين سال مطالعه با نسبت شانس بر آورد شده در مطالعات مختلف مشاهده شد برد اما معنى دارى نبود(9MM/P: (شكل F) (F). متغير هاى اختلالات روانى و حجم نمونه نيز تاثير معنى دارى بر

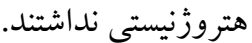
ارزيابى سو گرايى انتشار با استفاده از آزمون Begg 's test and Eggr 's شانس گزارش شده در مطالعات مختلف مشاهده

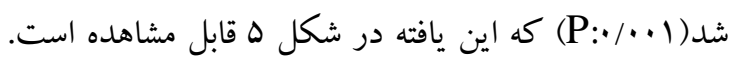

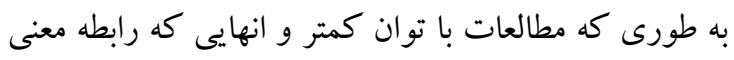
دارى نداشته بودند يا رابطه معكوسى مشاهده كرده بودند شانس كمترى براى جاب شدن داشتند. بمنظور تطبيق

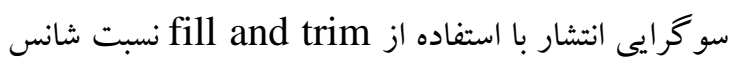
ادغام شده براى تورش انتشار اصلاح شد و مقدار آن 1/YN

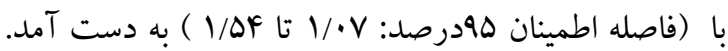

\section{يافته ها}

حجم نمونه مورد بررسى 9019VA نفر بود. از لا مقاله بررسى شده بنج مطالعه از نوع كوهورت (rا, 19-19) و شش مورد از نوع مورد شاهدى بود (D), (D) بر طبق جدول ا، جهار مطالعه ارتباط بين استرس و يره اكلاميسى، دو مطالعه اضطراب (19, ·Y)، دو مطالعه

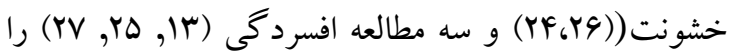
بررسى كرده اند، در ارتباط سنجى استرس با بروز يره

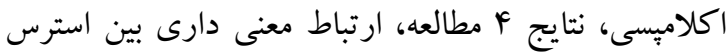

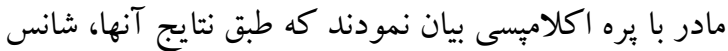
بروز يره اكلامِيسى در مادران داراى استرس به نسبت مادران بدون استرس بيشتر بود (Y). هم:جنين در ارتباط سنجى

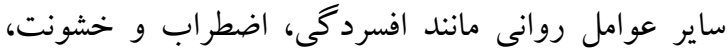
ارتباط معنى دارى مشاهده شد بطورى كه شانس بروز يره اكلاميسى در افراد داراى اضطراب، افسردگى، خشونت نسبت به افر اد كه اين مشكلات را نداشتند بيشتر بود. نسبت شانس كلى براى ارتباط سنجى عوامل روانى با بروز بره اكلامبسى برابر است با 1/91 با فاصله اطمينان

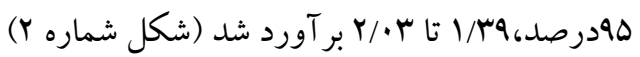
بر طبق شكل rا: در زير گروه استرس، نسبت شانس ابتلا به

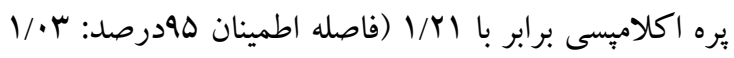
تا س/1)، در خشونت برابر با T/TV (فاصله اطمينان هودرصد:

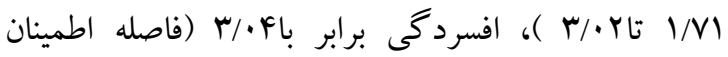

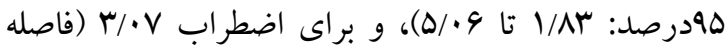

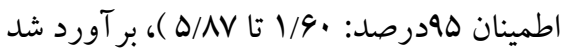

\begin{tabular}{|c|c|c|c|c|c|c|}
\hline فاصله اطمينان & شانست & حجم نمونه & نوع مطالعه & محل مطالعه & 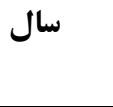 & نويسنده \\
\hline$r / f \Delta \Delta I / \cdot r$ & $r / T$ & rq.1 & كوهورت & 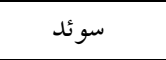 & $r \ldots q$ & 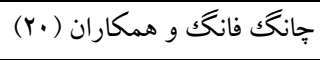 \\
\hline 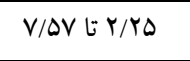 & $F / I r$ & mo. & كوهورت & آمريكا & $r .11$ & كريب و همكاران(19) \\
\hline 1/F\& 1/r| & 1/א & rar & مورد شاهد & 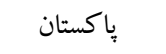 & $r \cdot 1$. & شمسى و همكاران (1ه) \\
\hline 1/TFF & $1 / / F$ & GFVTA & كوهورت & آلمان & $r .11$ & اسجنيدر و همكاران (YI) \\
\hline 1/^৭ا I/YI & $1 / 01$ & FVru & مورد شاهد & آمريكا & $r \cdot 1 r$ & يو و همكاران(Yr) \\
\hline 1//L • • & $1 / \cdot r$ & 11. & مورد شاهد & ايران & $r \cdot 1 r$ & معافى و همكاران(Yr) \\
\hline r/Ar I/FV & $r / r V$ & r.. & مورد شاهد & 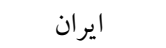 & $r \cdot 1 r$ & كردى و همكاران(ه) \\
\hline
\end{tabular}

همله علمى دانشكاه علوه بِزشكى كردستان / دوره بيست و شش / فروردين و ا(ديبرشت م.ع|| 
مرار ارتباط بين عواهل (وانى...

\begin{tabular}{|c|c|c|c|c|c|c|}
\hline 1/V I/ra & T/MG & qV9 & مورد شاهد & 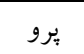 & $r \cdot \cdots$ & سانجز و همكاران (Y9) \\
\hline 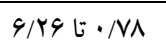 & $r / \cdot r$ & 999 & مورد شاهد & 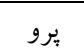 & $r \cdots V$ & جانگك فو و همكاران (rD) \\
\hline 1./IVا I/Aه & $F / M F$ & 999 & كوهورت & ايران & $r .10$ & معينى مهر و همكاران(r) \\
\hline 9/199 1/49 & $r / 9 \Delta$ & Yq1 & كوهورت & امريكا & $r \cdot 1 r$ & كيم و همكاران(YV) \\
\hline
\end{tabular}

جدول r. نتايج آناليز متار ترسيون يكطرفه

\begin{tabular}{|c|c|c|c|}
\hline مقدار احتمال & خطاى معيار & ضريب (حدود اطمينان 90٪) & متغير ها \\
\hline$\cdot /$ / & $\cdot / 1 \Delta \Delta$ & $(\cdot / \Delta 1 \cdot t \cdot / / 94) \cdot / 1 \Delta \mathrm{V}$ & اختلالات روانى \\
\hline $.1 \cdot 19$ & $\cdot / Y 9 \Lambda$ & $(1 / \uparrow \cdot \Delta ا \cdot / / \Lambda \Lambda) \cdot /$ V৭৭ & نوع مطالعه \\
\hline$\cdot / 911$ & $\cdot / \cdot v \Delta$ & $(\cdot / 911$ ا & سال جاب \\
\hline - MFY & $-9 / 9 \Delta \times 1 \cdot \cdot^{-v}$ & 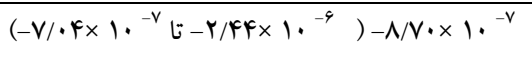 & حجم نمونه \\
\hline
\end{tabular}

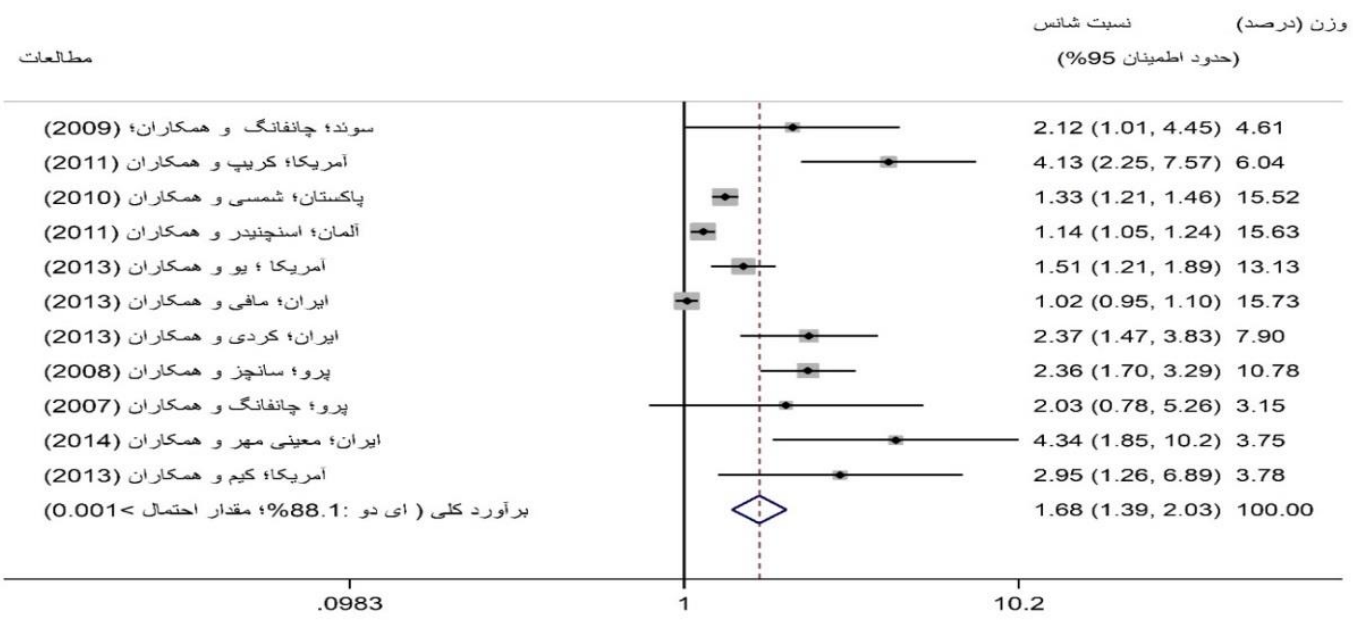

شكل r. عوامل روانى به تفكيك نويسنده، سال، نسبت شانس و فاصله اطمينان 9 درصد، هر ياره خط، طول فاصله اطمينان را نشان مى دهد

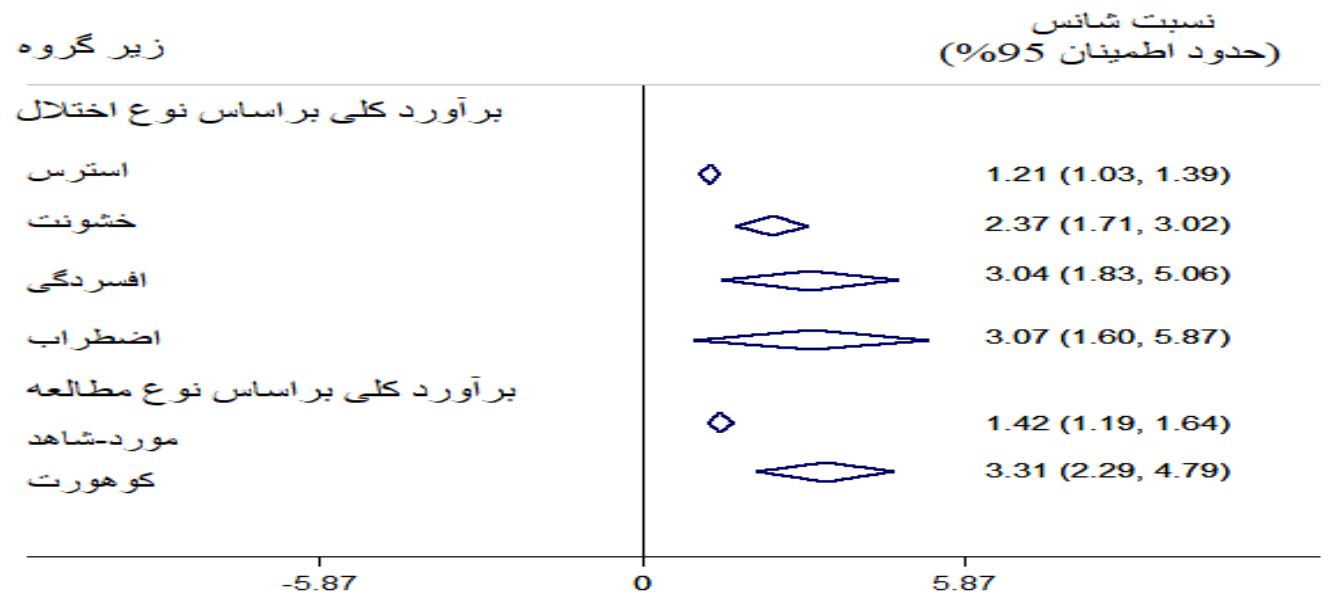

شكل "َ. برآورد ادغام شده نسبت شانس براساس هر زير كروه از عوامل روانى و نوع مطالعه 


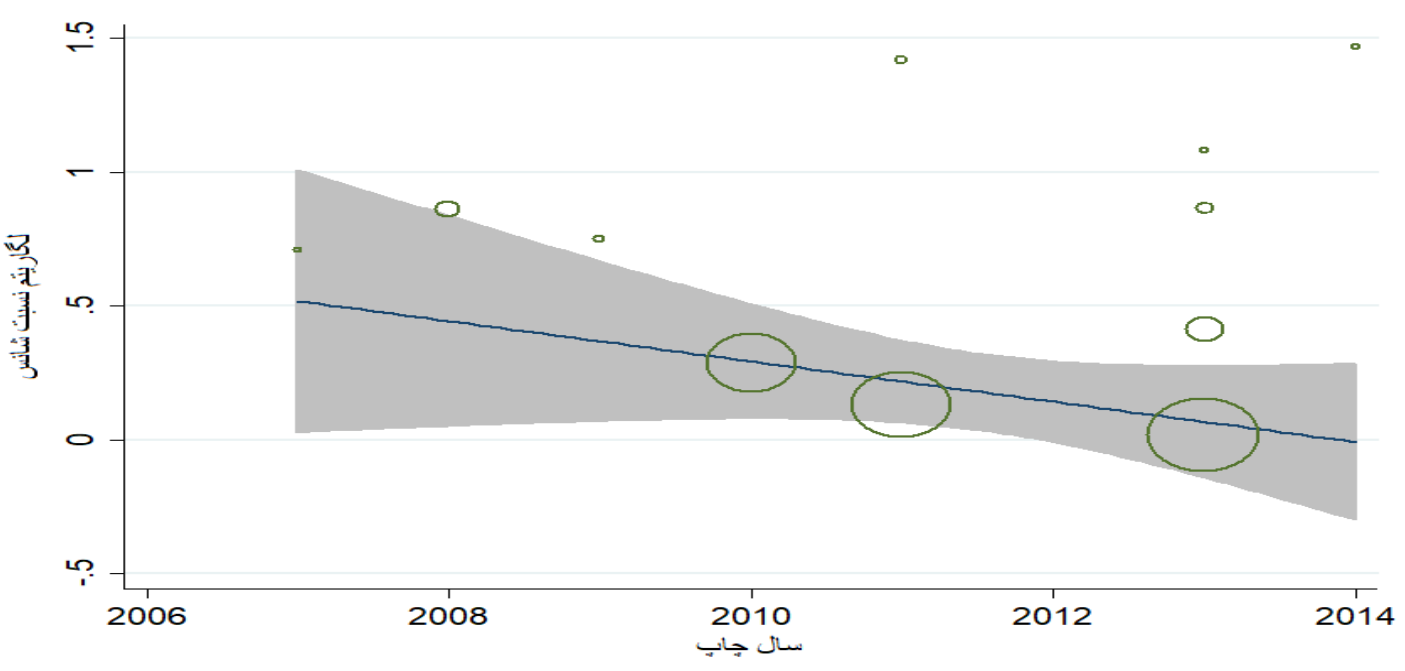

شكل ع. نمودار متارگرسيون ارتباط بين نسبت شانس عوامل روانى و سال مطالعه

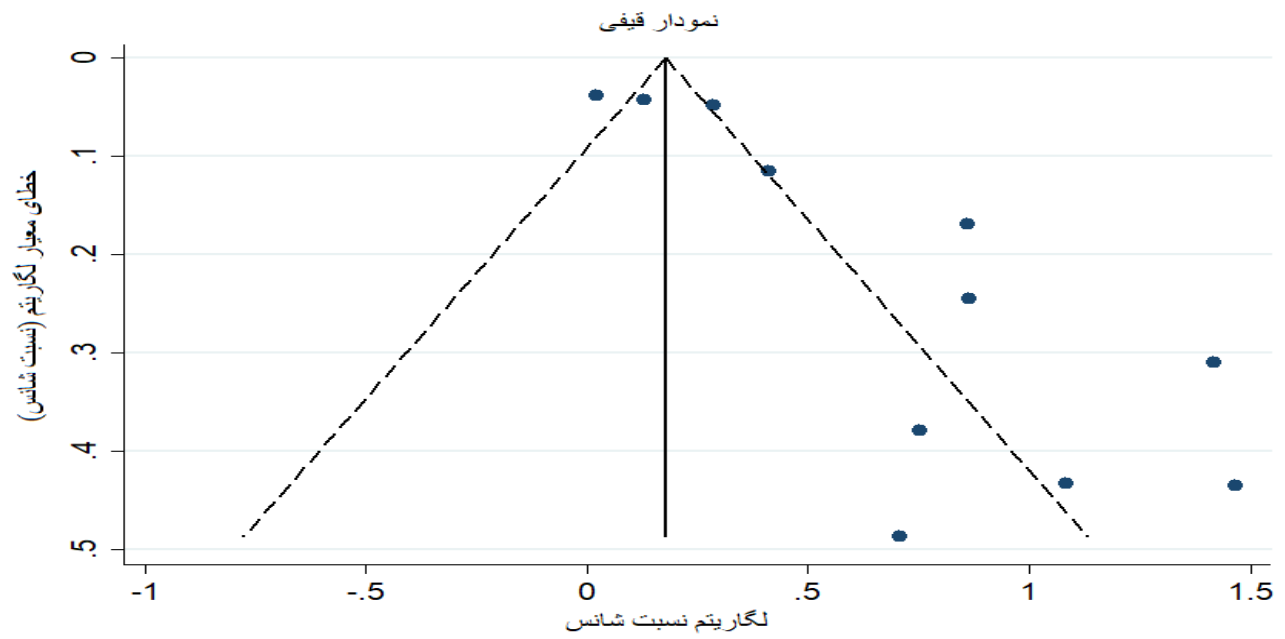

شكل 0. plot funnel براى مطالعات وارد شده به متا آناليز عوامل روانى

راستا با اين يزوهش، مطالعه شمسى و همكاران(ها)نيز كه

به منظور بررسى عوامل خطر :هره اكلاميسى در زنان ياكستانى انجام شد، حاكى از ميزان بيشتر استرس در زنان مبتلا به :بره اكلاميسى بود اسشيندر(Scheider) و همكارانش (YI)؛ در مطالعه خود نشان دادند زنان باردار داراى استرس روحى روانى بالا با احتمال بيشترى داراى بره

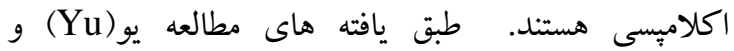
همكاران (YY)؛ استرس روانى اجتماعى و فشارخون بالا مى هـ

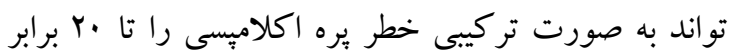
افزايش دهند. اين يافته بر اهميت تلاش براى بيشخيرى، طبق يافته هاى مطالعه حاضر، شانس بروز يره اكلاميسى در

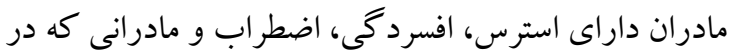
معرض خشونت واقع شده اند نسبت به افرادى كه اين مشكلات را نداشتند بيشتر بود. مطالعه حاضر اولين متا آناليزى است كه براى ارزيابى ارتباط بين عوامل روانى و

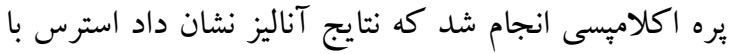
افزايش خطر ابتلا به بره اكلاميسى و فشار خون بالا همراه است. در مطالعه معافى و همكاران (Tr)، ميزان استرس دركك شده در زنان مبتلا به بِره اكلاميسى بيشتر بود. هم همله علمى دانشكاه علوه بِزشكى كردستان / دوره بيست و شش / فروردين و ا(ديبرشت م.ع|| 
عارسا ارتباط بين عواهل (وانى...

گوناگون، شر ايط فرهنگى متفاوت كه در تفسير برسشنامه و سبك باسخ نيز تاثير مى كذارد باشد. استرس هاى روانى با تغيير در سبكك زندگى و تغيير در سطح هورمون هاى محور هييو تالاموس - هييوفيز - آدرنالجفت در بروز بره اكلامِسى نقش دارند (ها). نتايج مطالعه حاضر با نتايج يكك مطالعه مبتنى بر بيمارستان بزرگك كه توسط بانسيل(Bansil) و همكاران انجام شده است همسو است (Y)). نتايج نشان مى دهد كه نه تنها افسردگى توسط مصاحبه تشخيص داده مى شود بلكه علائم افسردگى كه با

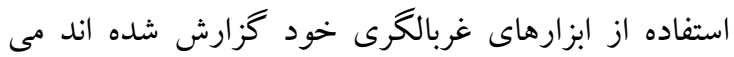
توانند تاثيرات منفى بر بيامدهاى باردارى مانند زايمان زودرس، وزن كم هنگام تولد و كاهش در شروع شيردهى داشته باشند (rV). نتايج مطالعه هو (Hu)و همكاران (rی)؛ تفاوت معنى دارى بين افسردگى و فشارخون باردارى

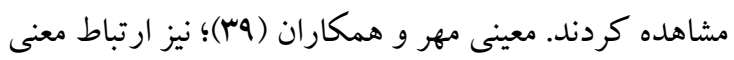
دارى بين افسردگى و فشارخون باردارى يافت كردند. نتايج مطالعه كيو(Qiu) و همكاران (Y..V. حاكى از ميزان بروز ץ-Y برابر يره اكلامتسى در زنان مبتلا به افسردگى در مقايسه با افراد بدون افسردگى مى باشد (YD). در مطالعه ولبرگت و همكاران (19)؛ نخرانى و افسردگى ناشى از باردارى در بروز هايبرتانسيون حاملكَى و پيره اكلاميسى

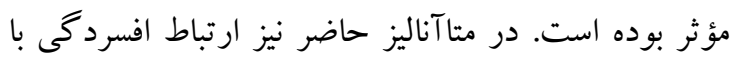
يروز يره اكلاميسى معنى دار شد، بنابراين بر اساس يّاتو فيزيولوزى هره اكلاميسى مى توان جنين بيان كرد كه افسردگى مى تواند سبب اختلال عملكرد هييو تالاموس هيبوفيز، اختلال سيستم ايمنى و فعال شدن هورمون ها و يره اكلامِسى گر دد (F). با توجه به محدود بودن مطالعات در اين زمينه(ارتباط افسردگى با بره اكلاميسى) نتايج مطالعه حاضر، حاصل آناليز مطالعاتى است كه افسردگى را بر طبق يرسشنامه سنجيده اند و افراد بطور بالينى تشخيص داده نشده بودند. كه نياز به انجام مطالعات در افراد كه بطور بالينى

$$
\text { افسردگى دارند احساس ميشود. }
$$

غربالكرى و اداره برفشارى خون و كاهش استرس روانى و وبرل اجتماعى بخصوص در ميان زنان مبتلا به فشارخون مزمن

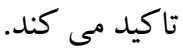
مجموعة درحسال گَسترشى از داده هـا، بيـانگر تـأثير نـامطلوب عوامـل روانى اجتماعى بر بيامدهاى باردارى . مانند افزايش استعداد ابتلا به عفونت، تهوع، افزايش فشارخون، زايمان زودرس و زايمان نوزادى با وزن كم هنگام تولد مى باشد (YN). يافته هاى مطالعه لينرز و همكاران (Y9)؛ بيانكر اين موضوع مى باشد كه استرس عـلاوه بـر تـأثير بـر بـروز بره اكلامِسى، با شدت آن و وخيمتر شدن بيمارى ارتبـاط معنى دارى دارد. موقعيت استرس آور، با تأثير مستقيم بر محسور هييوتالاموس و هييـوفيز و آدرنـال، سـبب افزايش سطوح كورتيزول شده و از اين طريق، به تغييراتى در ايمنى سلولى منجر خواهـــ شـد؛ افزايش ميزان كورتيزول نيز با افزايش فـشارخون و

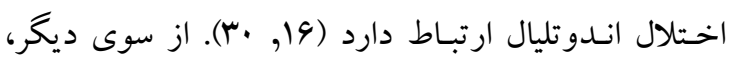
سازو كارهاى رفتارى ازجمله سبكك زندگى و رفتارهاى ناسالم و غيربهداشتى مانتـد كشيدن سـيكار، مـصرف مـواد مخدر و كم تحركى، مادر را مستعد بيماريهاى قلبى عروقى و عفونت ميكنند كه واكنشى بـه استرس است، و حاكى از تأثير غيرمستقيم استرس بر اين بيماريها مى باشد (آM). در مطالعه ولبرگت (19)؛ هيج ارتباطى بين استرس كار، اضطراب، افسردگى يا اضطراب مرتبط با باردارى در اوايل باردارى و برفشارى خون باردارى يا بره اكلامبسى بعد از باردارى ديده نشد. در مطالعه كركى(Kurki)و همكاران (Y)؛؛ ارتباط بين اضطراب و افسردكى با بروز يره اكلاميسى ديده شد. تحقيقات بيولوزيكى ارتباط بين عملكرد روانى و فشار خون بالا را احتمالا به علت تغييرات در جندين فر آيند

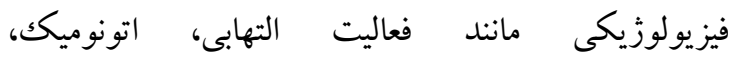
هييوتالاموس، هييوفيز و آدرنال مى دانند (بس, سM). تعدادى مطالعات ارتباط مثتى بين استرس و اضطراب مادر با

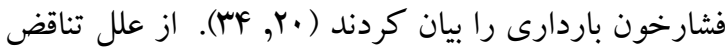
در نتايج مطالعات گوناگون مى توان استفاده از ابزارهاى 
مطالعات باو بدون تورش انتشار تفاوت معنى دارى نخو اهند داشت و در كل ميتوان كفت كه تورش انتشار در كل تغييرى در جهت رابطه ايجاد نكرده است. به طور خلاصه، متآناليز حاضر نشان مى دهد كه علائم افسردگى، از عوامل خطر براى بره اكلاميسى است. علاوه بر اين، افسردگى مى تواند منجر به فشار خون بالا به علت تغييراتى در محور هييوتالاموس-هييوفيز-آدرنال شود از آنجائيكه هيره اكلامبسى و فشار خون بالا ويثز را دارند، ممكن است افسردگى باعث ايجاد تغييرات مشابه شود و در نهايت باعث يره اكلاميسى شود. نظر به عوارض و بيامدهاى ناكوار يره اكلاميسى، لزوم توجه بيش از بِيش به عوامل خطر اين بيامد مهم باردارى مى تواند از اهميت بسيار بالايى برخوردار باشد. با توجه به نتايج مطالعه حاضر عوامل

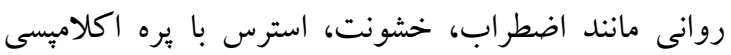
ارتباط معنى دارى داشتند، غربالخرى عوامل روانى و رون

رفتارى در هر سه ماهه باردارى ضرورى به نظر مى رسد.

نقاط قوت و ضعف مطالعه:

ارائه يكك نتيجه كلى حاصل شده از مطالعات بررسى همه جانبه مقالات در يايگاههاى اطلاعاتى، افزايش آشنايى و آكاهى محققين و دانشخاهيان در خصوص تاثير عوامل روحى روانى و بيشنهاد انجام مطالعات طولى و آينده نگر با حجم نمونه بالا جهت ارتباط سنجى بين اين عوامل مهم با هر كدام از ييامدهاى باردارى از نقاط قوت مطالعه حاضر مى باشد. از محدويت هاى مطالعه نيز مى توان به عدم دستيابى به

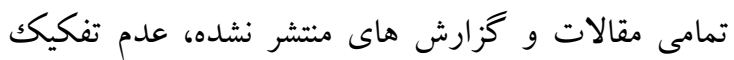
دقيق اختلالات روانيزشكى مرتبط با مولفه هاى مورد بررسى، استفاده از برسشنامه براى سنجش عوامل روانى و ذكر اين نكته كه مقالات در كشور هاى مختلف انجام شده در نتيجه منطقه جغرافيايى، عوامل محيطى و قوميت مى توانند بر روى عوامل روحى روانى و بيامدهاى باردارى اثر كذار باشد اشاره نمود لذا براى حذف نمودن اين محدوديت ها نياز به انجام مطالعات طولى در اين زمينه در هر منطقه احساس مى شود.
در بررسى ارتباط بين در معرض خشونت واقع شدن با شانس ابتلا به يره اكلاميسى، مطالعه كردى و همكاران(YF) بيشترين احتمال ابتلاء به يره اكلاميسى، مواجهه با خشونت روانى و در مرتبه بعدى، خشونت جنسى بود. نتايج اين مطالعه با نتايج مطالعه سانجز و همكاران(Y9)؛ در برو كه با هدف تعيين ارتباط بين خشونت خانگى با يره اكلاميسى

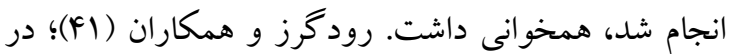
مطالعه مرورى خود تحت عنوان"آسيب هاى جنسى و باردارى "نشان دادند كه زنان تحت خشونت جنسى، بيشتر در معرض بيمارى هاى مزمن از جمله مشكلات قلبى، آرتريت، عفونت هاى تنفسى، فشارخون بالا و آسم قرار

دارند.

اختلالات فشارخون از مهم ترين مسائل حل نشده مامايى محسوب مى شوند به نظر مى رسد عوامل خطر ساز آن بخوبى مشخص نشده است. بررسى جنبه هاى روانى كه به دليل تحريك سيستم عصبى اتونوميك باعث فعاليت بيش از حد سيستم سمياتيكك مى شود به عنوان عامل خطر در اين اختلال لازم و ضرورى است. همجنين نياز به تلاش بيشتر يرسنل بهداشت و درمان براى بيشخيرى، غربالكرى و اداره يرفشارى خون و كاهش استرس روانى و اجتماعى . إنى بخصوص در ميان زنان باردار مى باشد زيرا با بيشخيرى از اين بيامد نامطلوب مى توان از مشكلات بعدى در مادر، نوزاد و حتى بار مالى و روانى كه بر دوش خانواده و جامعه مى گذارد جلو گيرى نمود. يكى از يافته هاى مطالعه ما وجود تورش انتشار در يافته هاى مطالعات مختلف بود به طورى كه مطالعاتى كه رابطه معنى دارى مشاهده نكرده بودند و يا رابطه معكوسى مشاهده كرده بودند شانس كمترى براى انتشار داشته اند كه اين مسئله ميتواند نتايج كلى متااناليز را تحت تاثير قرار دهد. نتايج fill and trim براى بررسى اثر تورش انتشار بر برآورد كلى ارتباط سنجى عوامل روانى با بروز بره اكلاميسى نشان داد كه با در نظر گرفتن مقالات جابٍ نشده نسبت شانس ميتواند عددى بين V// تا IF/ باشد با توجه به همبوشانى حدود اطمينان ها ميتوان نتيجه گرفت نتايج

همله علمى دانشكاه علوه بِزشكى كردستان / دوره بيست و شش / فروردين و ا(ديبرشت م.ع|| 
13. Moeinimehr M, Foroghipour A, Shokrani S, Goli S, Soleymani B. Depression during Pregnancy and Preeclampsia in third Trimester in Women Attending Prenatal Care Center of Esfahan iniran . J Res develop Nurs \& Midwifery. 2015;12(1):103-110.

14. Moafi F, Dolatian M, Keshavarz Z, Alavi Majd H, Dejman M. Relationship between social support and stress in pregnancy with preeclampsia. J Soc Welf. 2013;13(8):149-168.

15. Shamsi U, Hatcher J, Shamsi A, Zuberi N, Qadri Z, Saleem S. A multicentre matched case control study of risk factors for preeclampsia in healthy women in Pakistan. BMC women's health. 2010;10(1):14.

16. Vollebregt KC, Van Der Wal MF, Wolf H, Vrijkotte TG, Boer K, Bonsel GJ. Is psychosocial stress in first ongoing pregnancies associated with pre-eclampsia and gestational hypertension? BJOG. Int J Obstet Gynecol. 2008;115(5):607-15.

17. Tsang A, Von Korff M, Lee S, Alonso J, Karam E, Angermeyer MC, et al. Common chronic pain conditions in developed and developing countries: gender and age differences and comorbidity with depression-anxiety disorders. Jpain. 2008;9(10):883-91.

18. DerSimonian R, Laird N. Meta-analysis in clinical trials. Control Clin Trials. 1986;7:17788.

19. Cripe SM, Frederick IO, Qiu C, Williams MA. Risk of preterm delivery and hypertensive disorders of pregnancy in relation to maternal co-morbid mood and migraine disorders during pregnancy. Paediatr Perinat Epidemiol. 2011;25(2):116-23.

20. Qiu C, Williams MA, Calderon-Margalit R, Cripe SM, Sorensen TK. Preeclampsia risk in relation to maternal mood and anxiety disorders diagnosed before or during early pregnancy. Am J Hypertens. 2009;22(4):397-402.

21. Schneider S, Freerksen N, Maul H, Roehrig S, Fischer B, Hoeft B. Risk groups and maternal-neonatal complications of preeclampsia-current results from the national German Perinatal Quality Registry. J Perinat Med. 2011;39(3):257-65.

22.Yu Y, Zhang S, Wang G, Hong X, Mallow EB, Walker SO, et al. The combined association of psychosocial stress and chronic hypertension with preeclampsia. Am J Obstet Gynecol.. 2013;209(5):438. e1-. e12.

23.Moafi F, Dolatian M, Keshavarz Z, Alavi Majd H, Dejman M. Association between social support and maternal stress with preeclampsia. Soc Wel. 2013;13(48):151-70.

24. Kordi M, Nasiri S, Modaresgharavi M, Ebrahimzade S. The effect of problem solving skills training on severity of depression symptoms in postpartum period. J Fundament Mental Health. 2012;14:26-35.

25. Qiu C, Sanchez SE, Lam N, Garcia P, Williams MA. Associations of depression and depressive symptoms with preeclampsia: results from a Peruvian case-control study. BMC women's health. 2007;7(1):1-7.

26. Sanchez SE, Qiu C, Perales MT, Lam N, Garcia P, Williams MA. Intimate partner violence (IPV) and preeclampsia among Peruvian women. Eur J Obstet Gynecol Reprod Biol. 2008;137(1):50-5.

27. Kim DR, Sockol LE, Sammel MD, Kelly C, Moseley M, Epperson CN. Elevated risk of adverse obstetric outcomes in pregnant women with depression. Arch Womens Ment Health 2013;16(6):475-82.

28. Tuovinen S, Aalto-Viljakainen T, Eriksson J, Kajantie E, Lahti J, Pesonen AK, et al. Maternal hypertensive disorders during pregnancy: adaptive functioning and psychiatric and psychological problems of the older offspring. Obstet Gynecol Int J. 2014;121(12):1482-91.

29. Leeners B, Neumaier-Wagner P, Kuse S, Stiller R, Rath W. Emotional stress and the risk to develop hypertensive diseases in pregnancy. Pregnancy Hypertens. 2007;26(2):211-26. 
يسار ارتباط بين عواهل (وانى...

30. Vianna P, Bauer ME, Dornfeld D, Chies JAB. Distress conditions during pregnancy may lead to pre-eclampsia by increasing cortisol levels and altering lymphocyte sensitivity to glucocorticoids. Med Hypotheses . 2011;77(2):188-91.

31. Zachariah R. Social support, life stress, and anxiety as predictors of pregnancy complications in low-income women. Res Nurs \$ Health. 2009;32(4):391-404.

32. Meyer CM, Armenian HK, Eaton WW, Ford DE. Incident hypertension associated with depression in the Baltimore Epidemiologic Catchment area follow-up study. J Affect Disord. 2004;83(2):127-33.

33. Thombre MK, Talge NM, Holzman C. Association between pre-pregnancy depression/anxiety symptoms and hypertensive disorders of pregnancy. J Womens Health.. 2015;24(3):228-36.

34. Qin C, Dietz PM, England LJ, Martin JA, Callaghan WM. Effects of different dataediting methods on trends in race-specific preterm delivery rates, United States, 1990-2002. Paediatr Perinat Epidemiol. 2007;21(s2):41-9.

35. Seng JS. A conceptual framework for research on lifetime violence, posttraumatic stress, and childbearing. J Midwifery Womens Health .. 2002;47(5):337-46.

36. Bansil P, Kuklina EV, Meikle SF, Posner SF, Kourtis AP, Ellington SR, et al. Maternal and fetal outcomes among women with depression. J Women's Health. 2010;19(2):329-34.

37. Grigoriadis S, VonderPorten EH, Mamisashvili L, Tomlinson G, Dennis CL, Koren G, et al. The impact of maternal depression during pregnancy on perinatal outcomes: a systematic review and meta-analysis. J Clin Psychiatry. 2013;74(4):321-41

38. $\mathrm{Hu} \mathrm{R}$, Li Y, Zhang Z, Yan W. Antenatal depressive symptoms and the risk of preeclampsia or operative deliveries: a meta-analysis. PloS one. 2015;10(3):e0119018.

39. Moeinimehr M, Foroghipour A, Shokrani S, Goli S, Soleymani B. Depression during pregnancy and Preeclampsia in third Trimester in women attending prenatal care center of Esfahan in 2010-2012. J Res Develop in Nurs and Midwifery. 2015;12:103-110.

40. Byna P, Muvva N, Kolli S, Shaik MV. A study of risk factors and consequences of asymptomatic bacteriuria in pregnant women and feto-maternal outcome. Int $\mathrm{J}$ Reprod Contracept Obstet Gynecol. 2017;4(5):1300-5.

41. Rodgers CS, Lang AJ, Twamley EW, Stein MB. Sexual trauma and pregnancy: a conceptual framework. J Womens Health. 2003;12(10):961-70. 